\title{
A Rare and Atypical Case of Essential Cryoglobulinemic Glomerulonephritis with Crescents
}

Christopher Haas $^{1^{*}}$, Devinder Singh ${ }^{2}$, Pedram Kohan ${ }^{2}$, Suganthi Soundararajan ${ }^{3}$, and Sandeep Aggarwal ${ }^{4}$

${ }^{1}$ Drexel University College of Medicine, Philadelphia PA, USA

'Department of Medicine, Hahnemann University Hospital, Philadelphia PA, USA

${ }^{3}$ Department of Pathology, Hahnemann University Hospital, Philadelphia, PA, USA

${ }^{4}$ Department of Nephrology, Hahnemann University Hospital, Philadelphia, PA, USA

\begin{abstract}
We report a rare and atypical case of essential cryoglobulinemic glomerulonephritis with crescent formation in an 18yo African-American male that presented with recurrent microscopic hematuria, proteinuria, and mildly elevated creatinine. There was no antecedent history of purpura, rashes, or arthralgia/ myalgia, and autoantibodies as well as viral serology for HCV, HIV, and CMV were negative. Quantification of serum immunoglobulins was significant for an elevated IgM without the presence of rheumatoid factor and elevated kappa and lambda light chains. Kidney biopsy demonstrated sclerosis, interstitial inflammation, endocapillary and mesangial proliferation, and crescent formation. Immunofluorescent studies demonstrated granular deposits within the glomerular basement membrane and mesangium. Electron microscopy revealed podocyte foot process effacement and the presence of mesangial and subendothelial electron dense deposits of randomly arranged, slightly curved microtubular/ fibrillary structures that formed occasional fingerprints consistent with a diagnosis of cryoglobulinemic glomerulonephritis. The diagnosis was confirmed by the identification of serum cryoglobulins with subsequent immunofixation electrophoresis of the cryoprecipitate revealing a mixed cryoglobulinemia type III. Treatment with IV methylprednisolone, followed by oral prednisone and Rituximab was initiated with resolution of hematuria and normalization of creatinine.
\end{abstract}

Keywords: Essential cryoglobulinemia; Glomerulonephritis; Cryoglobulinemic glomerulonephritis; Crescents; Clinical case

\section{Introduction}

Cryoglobulinemic glomerulonephritis is a rare and particular subtype of membranoproliferative glomerulonephritis that occurs following the deposition of cryoglobulins in the kidney [1-5F. It is specifically characterized by a variety of histopathological phenomenon including glomerular hypercellularity, increased cellular matrix, duplication of the glomerular basement membrane, inflammatory cell invasion, eosinophilic subendothelial deposits, and a characteristic pattern of immunohistological and ultrastructural findings on fluorescent and electron microscopy, respectively [1-4,6-9]. In a limited number of cases, cryoglobulinemic glomerulonephritis has been associated with crescent formation [3,10-12], a rare pathological phenomenon characterized by damage to the glomerular basement membrane and progressive scarring of the functional kidney unit, the nephron. On a structural level, this phenomenon involves a delicately orchestrated series of events including a sustained inflammatory reaction resulting in epithelial, mesangial, and endothelial cell proliferation, leukocyte and fibroblast invasion, and deposition of fibrin and collagen, leading to hematuria, proteinuria, and gradual loss of kidney function [13-18].

Though the pathophysiological mechanisms leading to the progressive decline of kidney function in the setting of membranoproliferative glomerulonephritis involve a myriad of factors, cryoglobulin-containing immune complex deposition is an inciting event. Cryoglobulinemia is often associated with lymphoproliferative disorders, such as multiple myeloma or Waldenstrom's macroglobulinemia, connective tissue disorders, such as Systemic Lupus, or infectious etiologies, such as Hepatitis C, with the majority of cases manifesting in middle aged females in the $4^{\text {th }}-5^{\text {th }}$ decade of life [6]. In these cases a classical clinical triad of purpura, arthralgia, and weakness has been described [19-23], which generally precedes and progresses to renal involvement in approximately one-third of cases $[24,25]$. Intriguingly, in less than ten percent of cases no underlying cause for cryoglobulinemia has been found, and such cases have been termed 'essential' $[21,23,26]$. Furthermore, a rare subset of cases present with renal involvement in the form of microscopic hematuria or proteinuria, in the absence of systemic signs or symptoms [3,27]. In this report, we present a case of an $18 \mathrm{y}$ African-American male with recurrent microscopic hematuria and proteinuria, without other systemic symptoms, and who was found to have pathology consistent with cryoglobulinemic glomerulonephritis.

\section{Case Presentation}

An 18yo incarcerated African-American male with a past medical history significant for intermittent asthma presented to our hospital following repeated urine dipsticks and urinalyses significant for hematuria and proteinuria found incidentally on routine laboratory studies dating from five months prior to admission. The patient denied significant symptomatology and also denied significant past medical/ surgical history, medication use, or family history of renal disease or connective tissue diseases. The patient denied alcohol and illicit substance use, but assented to smoking approximately 1-2 cigarettes on a daily basis.

Throughout the course of hospitalization, the patient remained afebrile, maintained a heart rate of $60-70 \mathrm{bpm}$ and a blood pressure that ranged from 110-135 systolic / 60-85 diastolic, and an oxygen saturation above $98 \%$. On physical exam, the patient was a healthy appearing male in no acute distress, with no abnormalities appreciated. Of note, there were no oral ulcers, no observable rashes, petechiae, or purpura, no

*Corresponding author: Christopher Haas, Drexel University College of Medicine 2900 W Queen Lane, Philadelphia, PA 19129, USA, Tel: 917-225-4724; E-mail: cjh62@drexel.edu

Received: October 19, 2015; Accepted: October 28, 2015; Published: November 04, 2015

Citation: Haas C, Singh D, Kohan P, Soundararajan S, Aggarwal S (2015) A Rare and Atypical Case of Essential Cryoglobulinemic Glomerulonephritis with Crescents. J Nephrol Ther 5: 220. doi:10.4172/2201-0959.1000220

Copyright: (c) 2015 Haas C, et al. This is an open-access article distributed under the terms of the Creative Commons Attribution License, which permits unrestricted use, distribution, and reproduction in any medium, provided the original author and source are credited. 
lymphadenopathy, no hepatosplenomegaly, no CVA tenderness, and no edema. Laboratory studies were performed and are reported in Table 1. Antibodies to ANCA, dsDNA, Glomerular Basement Membrane, SSA, SS-B, Smith, RNP, Scleroderma (Scl70), Rheumatoid Factor, AntiStreptolysin O, and Anti-cyclic Citrullinated Peptide (CCP) were all negative. Hepatitis $\mathrm{B}$ and Hepatitis $\mathrm{C}$ panel (antigens and antibodies) were non-reactive and there was no evidence of viral titers. HIV status and TB was also negative. Immunoglobulins of the IgG subtype were elevated to EBV Viral Capsid Antigen and Nuclear antigen, however EBV IgM and early IgG antibodies, as well as viral DNA PCR analyses, were negative, consistent with prior infection. Levels of serum immunoglobulins of the IgM subtype as well as kappa and lambda light chains were elevated. Serum protein electrophoresis was significant only for decreased albumin without any abnormalities in total globulin, alpha globulins, beta globulins, gamma globulins, or the presence of an M-spike. Analyses for cryoglobulins were positive at 72 hours, with resultant cryoprecipitate immunofixation electrophoresis revealing a type III mixed cryoglobulinemia. Total complement, C3, and C4 were all within normal limits.

Urine analyses included a urine dip, microscopy, urine chemistry, and $24 \mathrm{~h}$ urine electrophoresis. Urine dip was significant for the presence of $2+$ protein and $3+$ blood in the setting of a urine specific gravity of 1.013, with 31-50 RBC and 1-4 hyaline casts/hpf on microscopic analysis. Urine chemistry and urine protein electrophoresis were significant only for the presence of elevated protein. Random urinary protein to creatinine ratio at presentation was 1.60 , serving as a surrogate marker of daily protein excretion. Urine drug screen was negative for illicit substances.

Bilateral renal ultrasound with color Doppler imaging revealed normally sized kidneys with increased cortical echogenicity and no evidence of hydronephrosis, contour-deforming masses, calculi, or perinephric fluid accumulations. The patient subsequently underwent a percutaneous ultrasound guided biopsy of the left kidney, with specimens sent for histological, immunological, and electron microscopy analysis. Light microscopy of H\&E stained sections revealed moderate interstitial fibrosis, tubular atrophy, and mixed interstitial inflammation composed of lymphocytes, plasma cells, neutrophils, eosinophils, and rare macrophages. Thirty-two glomeruli were identified, of which the vast majority were enlarged with endothelial and mesangial hypercellularity and shrunken Bowman's spaces. Eight glomeruli demonstrated significant amounts of sclerosis and an additional eight glomeruli demonstrated crescent formation (Figure 1). Jones' silver staining revealed focal basement membrane duplication, while trichrome staining demonstrated the presence of eosinophilic intraglomerular deposits as well as collagen deposition within Bowman's space (Figure 2). There was no evidence of wire-loop lesions of intracapillary protein thrombi. Immunofluorescence staining revealed the presence of granular deposits that were strongly positive for IgG, IgM, C3, C1q and kappa light chains with mild staining for IgA, C4, and lambda light chains (Figure 3). Electron microscopy revealed effacement of over $80 \%$ of podocyte foot processes and the presence of substantial subendothelial electron dense deposits of randomly arranged, slightly curved microtubular/ fibrillary structures 20-20.5 nm in diameter that formed occasional fingerprints (Figure 4). Taken together, the spectrum of clinical and pathological findings was suggestive of a diagnosis of membranoproliferative glomerulonephritis secondary to cryoglobulinemia (cryoglobulinemic glomerulonephritis).

\section{Outcome and Follow-Up}

The patient was loaded with IV methylprednisolone $500 \mathrm{mg}$ daily for three days and subsequently received $60 \mathrm{mg}$ prednisone and 1000 mg Rituximab. Flow cytometry following Rituximab administration revealed no immunophenotypically abnormal cell populations with a complete absence of CD20+ cells. One month following admission the patient presented for a second course of Rituximab therapy and was found to have diminished microscopic hematuria (11-20 RBC/hpf), diminished urinary protein $(191 \mathrm{mg} / \mathrm{dL})$ to creatinine $(189 \mathrm{mg} / \mathrm{dL})$ ratio of 1.01 from 1.60, and stabilization of his serum creatinine (1.21 $\mathrm{mg} / \mathrm{dL}$ ). Repeat analysis three months following initial presentation revealed a sustained suppression of $\mathrm{CD} 20+\mathrm{B}$ cells and continued improvement in laboratory parameters with further reductions in microscopic hematuria $(6-11 \mathrm{RBC} / \mathrm{hpf})$ and serum creatinine $(1.00$ $\mathrm{mg} / \mathrm{dL})$.

\section{Discussion}

In the most straightforward terms, cryoglobulinemia is defined as the presence of cryoglobulins in the blood [6]. In the clinical laboratory setting, cryoglobulins immunoglobulins that undergo reversible precipitation following exposure to cold temperature [26], assuming appropriate and strict handling techniques $[26,28]$. In reality, however, the precipitation of cryoglobulins and their deposition in situ likely involves a complex interplay of a variety of factors affecting protein solubility - primary protein structure, abundance of hydrophobic residues, steric conformation, decreased galactose or sialic acid in glycosylated regions, serum $\mathrm{pH}$, serum chloride concentration, and immune complex formation [21,26,28-32]. The deposition of these immune complexes in end organs has been shown to mediate end organ damage via a variety of different mechanisms including activation of innate Toll-like receptors, complement, and engagement of $\mathrm{Fc}$ receptors. Together, activation of these pathways results in propagation of an inflammatory cascade leading to cellular injury and the secretion of growth factors, such as PDGF and TGF $\beta$, that promote epithelial cell proliferation and matrix deposition [1,14,16-18,33]. Furthermore, monocytes appear to play a critical role in the clearance of deposited cryoglobulins and are often found not only in close proximity to such deposits, but also to be laden with amorphous protein droplets [34], prompting one study to highlight the potential for monocyte dysfunction as an underlying etiology of end organ damage [11,35].

Brouet and colleagues have classified cryoglobulinemia into three main categories, with the latter two categories classified as "mixed cryoglobulinemia" due to the presence of multiple antibodies [6,25]. Type I cryoglobulinemia is a monoclonal immunoglobulinemia commonly found in multiple myeloma, Waldenstrom's macroglobulinemia, or idiopathic monoclonal gammopathy, whereas the Type II and Type III mixed cryoglobulinemias contain monoclonal IgM and polyclonal IgG or polyclonal IgM and polyclonal IgG, respectively [25]. Mixed cryoglobulinemia has been associated with a variety of etiological factors - autoimmune (e.g. Systemic lupus erythematosus and Sjogrens Syndrome) and infection (e.g. HCV) - with less than $10 \%$ of cases labeled as 'essential', with no underlying etiology. Despite the absence of an underlying etiology, a variety of reports have suggested that cryoglobulinemia is a disorder of B lymphocyte expansion, whether in the context of lymphoproliferative disorders or in the context of persistent immune stimulation in the setting of autoimmunity or chronic infection $[1,21,36]$. Infection with Epstein Barr Virus (EBV) and the production of IgG subtype antibodies to the viral capsid antigen, as seen in our patient, was also seen in patients with essential mixed cryoglobulinemia [36]. Furthermore Fiorini and colleagues hypothesized that not only are EBV-infected B lymphocytes cleared more slowly, resulting in a greater number of antigen-bearing cells that 
Citation: Haas C, Singh D, Kohan P, Soundararajan S, Aggarwal S (2015) A Rare and Atypical Case of Essential Cryoglobulinemic Glomerulonephritis with Crescents. J Nephrol Ther 5: 220. doi:10.4172/2201-0959.1000220

Page 3 of 7

\begin{tabular}{|c|c|}
\hline Serum Chemistry & \\
\hline Sodium & $137 \mathrm{mmol} / \mathrm{L}$ \\
\hline Potassium & $4.1 \mathrm{mmol} / \mathrm{L}$ \\
\hline Chloride & $102 \mathrm{mmol} / \mathrm{L}$ \\
\hline $\mathrm{CO}_{2}$ & $28 \mathrm{mmol} / \mathrm{L}$ \\
\hline Calcium & $9.3 \mathrm{mg} / \mathrm{dL}$ \\
\hline Blood Urea Nitrogen & $17 \mathrm{mg} / \mathrm{dL}$ \\
\hline Creatinine & $1.23 \mathrm{mg} / \mathrm{dL}$ \\
\hline Total Protein & $7.5 \mathrm{~g} / \mathrm{dL}$ \\
\hline Albumin & $3.2 \mathrm{~g} / \mathrm{dL}(\mathrm{L})$ \\
\hline Bilirubin Total & $0.32 \mathrm{mg} / \mathrm{dL}$ \\
\hline Alkaline Phosphatase & $37 \mathrm{IU} / \mathrm{L}$ \\
\hline ALT & $10 \mathrm{IU} / \mathrm{L}$ \\
\hline AST & $22 \mathrm{IU} / \mathrm{L}$ \\
\hline Magnesium & $1.8 \mathrm{mg} / \mathrm{dL}$ \\
\hline Phosphate & $3.0 \mathrm{mg} / \mathrm{dL}$ \\
\hline Iron & $47 \mathrm{mcg} / \mathrm{dL}$ \\
\hline Total Iron Binding Capacity & $305 \mathrm{ng} / \mathrm{mL}$ \\
\hline Ferritin & $108 \mathrm{ng} / \mathrm{dL}$ \\
\hline Transferrin & $218 \mathrm{mg} / \mathrm{dL}$ \\
\hline CRP & $4.1 \mathrm{mg} / \mathrm{L}$ \\
\hline ESR & $49 \mathrm{~mm} / \mathrm{hr}$ \\
\hline Coagulation Studies & \\
\hline PT & $11.8 \mathrm{~s}$ \\
\hline PTT & $37.2 \mathrm{~s}$ \\
\hline INR & 1.09 \\
\hline C3 complement & $149 \mathrm{mg} / \mathrm{dL}$ \\
\hline C4 complement & $30 \mathrm{mg} / \mathrm{dL}$ \\
\hline Total Complement & 49 Units/mL \\
\hline Fibrinogen & $464 \mathrm{mg} / \mathrm{dL}$ \\
\hline Immunology/ Serology & \\
\hline Anti-streptolysin O & 77.9 IN Units/mL \\
\hline Atypical p-ANCA & $<1: 20$ \\
\hline Cytoplasmic C-ANCA & $<1: 20$ \\
\hline Perinuclear P-ANCA & $<1: 20$ \\
\hline Glomerular Basement Membrane Antibody & 7 Units \\
\hline Cyclic Citrullinated Peptide IgG/ IgA & 10 Units \\
\hline Antinuclear (ANA) Screen & Negative \\
\hline Scleroderma CL70 & 0.2 Units \\
\hline Smooth Muscle & 6 Units \\
\hline Double-stranded DNA & $4 \mathrm{IU}$ \\
\hline SS-A & $<0.2$ Units \\
\hline SS-B & 0.4 Units \\
\hline Ribonuclear Protein & $<0.2$ Units \\
\hline Rheumatoid Factor & $<10 \mathrm{IU} / \mathrm{mL}$ \\
\hline Smith & $<0.2$ \\
\hline Immunoglobulin A & $268 \mathrm{mg} / \mathrm{dL}$ \\
\hline Immunoglobulin G & $1580 \mathrm{mg} / \mathrm{dL}$ \\
\hline Immunoglobulin M & $518 \mathrm{mg} / \mathrm{dL}(\mathrm{H})$ \\
\hline CMV DNA Quant & $<200$ copies \\
\hline EBV Early lgG & $<9$ Units/mL \\
\hline EBV Viral Capsid Antigen IgM & $<36$ Units/mL \\
\hline EBV Viral Capsid Antigen IgG & 97.9 Units $/ \mathrm{mL}(\mathrm{H})$ \\
\hline EBV Nuclear IgG & 155 Units/mL $(\mathrm{H})$ \\
\hline EBV DNA PCR RT & Negative \\
\hline Hepatitis A IgM & Non-reactive \\
\hline Hepatitis B Surface Antigen & Non-reactive \\
\hline
\end{tabular}


Citation: Haas C, Singh D, Kohan P, Soundararajan S, Aggarwal S (2015) A Rare and Atypical Case of Essential Cryoglobulinemic Glomerulonephritis with Crescents. J Nephrol Ther 5: 220. doi:10.4172/2201-0959.1000220

Page 4 of 7

\begin{tabular}{|c|c|}
\hline Hepatitis B Core IgM & Non-reactive \\
\hline Hepatitis B Surface Antibody & Non-reactive \\
\hline HBV IU $/ \mathrm{mL}$ & $<20$ \\
\hline HBV log 10 & Negative \\
\hline Hepatitis C Antibody & Non-reactive \\
\hline Hepatitis C PCR RT & Not detected \\
\hline HIV $1 / 2$ Screen & Non-reactive \\
\hline HIV1 RNA PCR Quantification & Not detectable \\
\hline TB Screen & Negative \\
\hline \multicolumn{2}{|l|}{ Additional Serology } \\
\hline Lambda Light Chain & $49.97 \mathrm{mg} / \mathrm{L}$ \\
\hline Kappa Light Chain & $22.52 \mathrm{mg} / \mathrm{L}$ \\
\hline Kappa/ Lambda R & 0.45 \\
\hline Cryoglobulin Quantification & Positive @ 72h \\
\hline Immunofixation & Mixed Cryoglobulinemia, Type III \\
\hline \multicolumn{2}{|l|}{ Serum Protein Electrophoresis } \\
\hline Globulin Total & $3.7 \mathrm{~g} / \mathrm{dL}$ \\
\hline Albumin & $3.0 \mathrm{~g} / \mathrm{dL}(\mathrm{L})$ \\
\hline Alpha 1 Globulin & $0.2 \mathrm{~g} / \mathrm{dL}$ \\
\hline Alpha 2 Globulin & $1.0 \mathrm{~g} / \mathrm{dL}$ \\
\hline Beta Globulin & $0.9 \mathrm{~g} / \mathrm{dL}$ \\
\hline Gamma Globulin & $1.5 \mathrm{~g} / \mathrm{dL}$ \\
\hline M-spike & Not Observed \\
\hline Protein Total & $6.7 \mathrm{~g} / \mathrm{dL}$ \\
\hline \multicolumn{2}{|l|}{ Urinalysis } \\
\hline UA Specific Gravity & 1.013 \\
\hline UA pH & 6.0 \\
\hline UA Protein & $2+$ \\
\hline UA Blood & $3+$ \\
\hline UA WBC & $6-10$ \\
\hline UA RBC & $31-50$ \\
\hline UA Hyaline Casts & $1-4$ \\
\hline \multicolumn{2}{|l|}{ Urine Chemistry } \\
\hline Urine Chloride & $128 \mathrm{mmol} / \mathrm{L}$ \\
\hline Urine Creatinine & $154 \mathrm{mg} / \mathrm{dL}$ \\
\hline Urine Osmolality & $657 \mathrm{mOsm} / \mathrm{kg}$ \\
\hline Urine Potassium & $24.9 \mathrm{mmol} / \mathrm{L}$ \\
\hline Urine Protein & $246 \mathrm{mg} / \mathrm{dL}$ \\
\hline Urine Sodium & $141 \mathrm{mmol} / \mathrm{L}$ \\
\hline Urine Protein/ Creatinine Ratio & 1.60 \\
\hline \multicolumn{2}{|l|}{ Urine Protein Electrophoresis } \\
\hline Protein Total & $178.8 \mathrm{mg} / \mathrm{dL}$ \\
\hline Albumin & $80 \%$ \\
\hline Alpha 1 Globulin & $3.4 \%$ \\
\hline Alpha 2 Globulin & $4.1 \%$ \\
\hline Beta Globulin & $9.1 \%$ \\
\hline M-spike & Not Observed \\
\hline
\end{tabular}

Table 1: Laboratory findings at presentation.

provide a continuous stimulus for antibody production [6,36], but also that EBV viral DNA is incorporated into marrow blasts, providing a continuous reservoir for chronic, recurrent infection and cryoglobulin production $[34,37]$

The prevalence of 'essential' mixed cryoglobulinemia has been reported to be less than $1: 100,000[1,38]$ and is characterized as a myriad of clinical manifestations including purpura, arthralgia and weakness, with variable end-organ involvement $[1,6,21,38]$. Renal involvement takes an indolent course, presenting with microscopic hematuria, proteinuria, and an elevated serum creatinine in approximately $50 \%$ of patients [11,21-23,26,34,38]. Histologically, renal involvement manifests as a particular subtype of membranoproliferative glomerulonephritis in the setting of systemic symptoms, but rare cases, present with renal disease as the sole manifestation of the disease $[3,6,10]$, as seen in our patient. Furthermore, a small number of reports have demonstrated crescent formation on the background a cryoglobulinemic glomerulonephritis, a hallmark of severe disease [3,10,11,13,21].

The diagnosis of mixed cryoglobulemia revolves around 


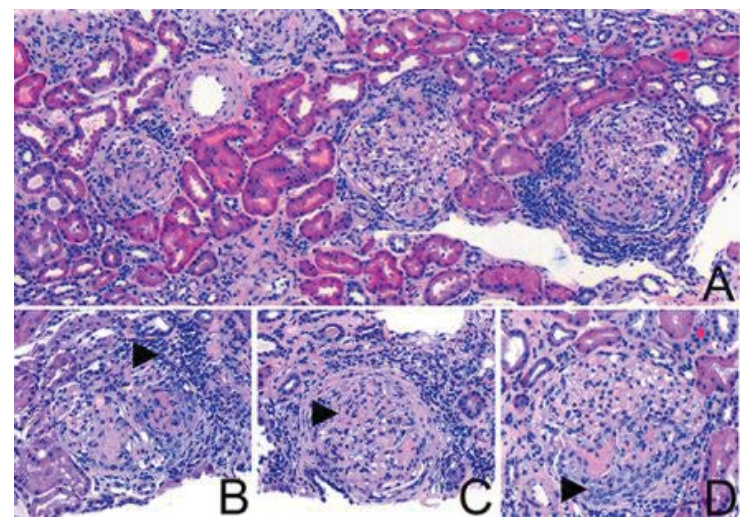

Figure 1: H\&E-stained kidney biopsy sections.Low magnification images reveal moderate interstitial fibrosis, tubular atrophy, mixed interstitial inflammation in the peri-glomerular region (A) with interstitial inflammation highlighted in Panel B (arrowhead). The majority of glomeruli are enlarged with evidence of endothelial and mesangial hypercellularity and obliteration of Bowman's space (A). Significant focal and global glomerular sclerosis is apparent (Panel $\mathrm{C}$, arrowhead) with evidence of crescent formation (Panel D, arrowhead). Panel A, 40x; Panels B-D, 100x.

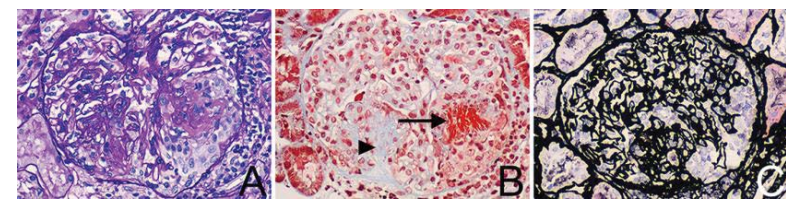

Figure 2: Immunohistological preparation of kidney biopsy sections with PAS, Trichrome, and Jones' silver stains. Histological preparation of kidney biopsy sections with PAS (A) reveals significant mucopolysaccharide deposition. Trichrome stain (B) reveals eosinophilic intraglomerular deposits (arrow) and collagen deposition (arrowhead), with obliteration of Bowman's space. Jones' silver stain (C) demonstrates diffuse thickening of the glomerular basement membrane with double-contours in the setting of focal/ global sclerosis and crescent formation. Panels A-C, 400x.
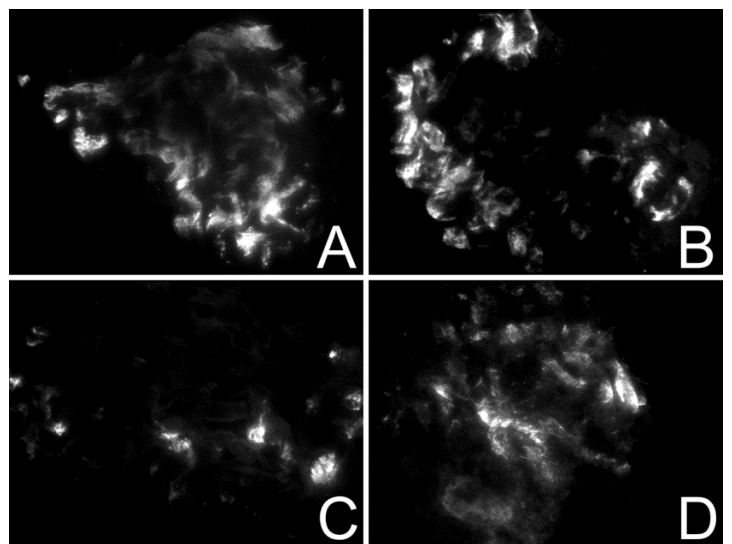

Figure 3: Immunofluorescent preparation of kidney biopsy sections with complement and Immunoglobulin antibodies. Staining with C1q (A), C3 (B), $\lg G(C)$, and $\lg M(D)$ reveals the presence of granular deposits found within similar regions on adjacent tissue sections. Panels A-D, 400x.

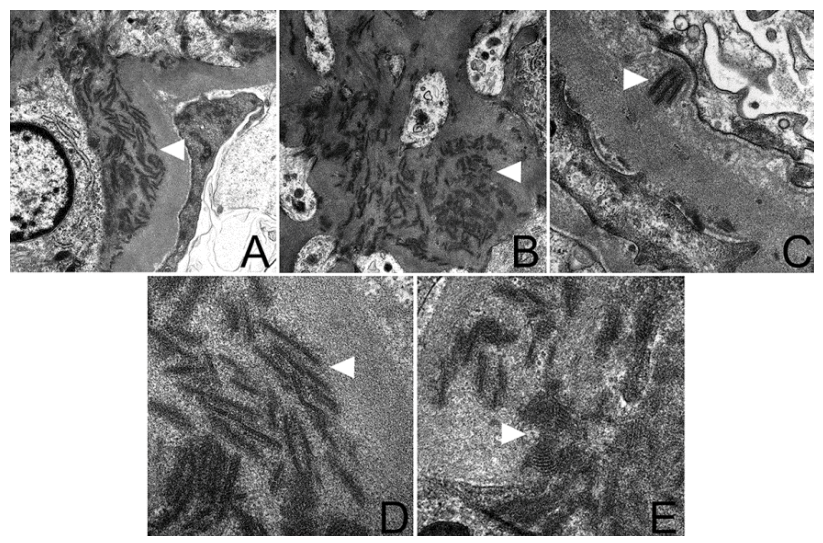

Figure 4: Electron Microscopy of kidney biopsy sections.Electron microscopy imaging reveals effacement of over $80 \%$ of podocyte foot processes and presence of substantial subendothelial $(A)$ and mesangial (B), with rare subendothelial (C) electron dense deposits of randomly arranged, slightly curved microtubular/ fibrillary structures of approximately $20-25 \mathrm{~nm}$ in diameter. High magnification images are shown in $D$ and $E$, and revealed that occasionally, these structures formed a fingerprint pattern $(E)$, consistent with a diagnosis of cryoglobulinemic glomerulonephritis. A-C = 30000x, D-E = 120000x.

characteristic clinical (e.g. purpura, arthritis, and glomerulonephritis) and laboratory findings (e.g. isolation of cryoglobulins, low levels of $\mathrm{C} 4$ and $\mathrm{C} 1 \mathrm{q}$, and high titers of rheumatoid factor) [6,21]. A variety of reports, however, have noted variable serological patterns [38] ranging from the complete absence of serum cryoglobulins [34,3840] to completely normal levels of complement proteins [3]. Of note, it has been demonstrated that levels of cryoglobulins can fluctuate significantly resulting in the potential for false-negative results, making serial assays necessary for proper diagnosis [21,26,28]. Intriguingly, four initial serum samples for cryoglobulins were negative, whereas a fifth sample demonstrated the presence of cryoglobulins at 72 hours of incubation, highlighting the need to repeat laboratory analyses in the setting of high clinical suspicion. It is important to recognize that in cases where the clinical suspicion for cryoglobulinemia is high, a negative test for cryoglobulins does not exclude a diagnosis of cryoglobulinemia $[21,28]$.

The course of cryoglobulinemic glomerulonephritis is variable. One-third of patients achieve partial or complete remission, another third have an indolent disease course that may progress to renal insufficiency years later, while one-third experience reversible clinical exacerbations even in the setting of appropriate treatment $[3,34]$. Progression to end stage renal disease and sclerosing nephritis has been reported as an uncommon event [10]. Though a variety of prognostic indicators have been proposed as independent risk factors for progression to end stage renal disease and mortality - older age, purpura, elevated plasma creatinine on presentation, and low $\mathrm{C} 3$, the subjects of this study were primarily Italian, middle-aged, co-infected with HCV, and had systemic signs of disease [10]. The patient in this case report, in contrast, was a young African-American male who presented with recurrent microscopic hematuria and proteinuria in the absence of systemic signs or symptoms, a negative HCV status, and normal complement levels. Furthermore, on renal biopsy the patient was noted to have significant crescent formation as well has focal and global glomerulosclerosis in $25 \%$ of his glomeruli at presentation, suggesting a more advanced disease process. Intriguingly, mixed cryoglobulinemia has been regarded as continuum along a spectrum 
that spans autoimmunity/ persistent infection and cancer [21,41], with B cell lymphoma the most frequent neoplastic manifestation [3,21$23,38,42,43]$. In these studies, lymphomas were found to arise in the setting of persistent B lymphocyte infection, such as in the setting of chronic infection and also due to lymphocytic infiltration in major organs, such as the bone marrow $[41,42,44]$ and heralded by a sudden decrease or disappearance of serum cryoglobulins [45]. Given the potential for malignant transformation, repeated longitudinal clinical evaluation is warranted.

Though no clinical trial has evaluated their efficacy, the mainstay of therapy for individuals with cryoglobulinemic glomerulonephritis has been the use of high dose conventional immunosuppressants such as methylprednisolone followed by prednisone $[21,38,46]$. In an increasing number of cases biological therapies, targeting specific aspects of disease pathogenesis, have emerged as concomitant first line therapies. Given the intricate link between mixed cryoglobulinemia and aberrant $B$ lymphocyte antibody production, proliferation, and elimination, the anti-CD20 monoclonal antibody, Rituximab, has been frequently used to control disease. A variety of small reports have demonstrated clinical efficacy in the setting of moderate disease and have highlighted that relapses recur in the setting of B lymphocyte recovery $[13,21,47,48]$. The patient presented in this report received successful Rituximab therapy that led to a complete elimination of peripheral CD20+ B lymphocytes, as verified by flow cytometry. In addition to conventional therapy, a variety of other interventions targeting improved monocyte clearance of circulating cryoglobulins and deposited complexes of cryoglobulins, via dietary modification, and reduction of intraglomerular filtration pressure, via ACE inhibitors, have been proposed [30,38], and require further evaluation in carefully designed clinical trials.

\section{Conclusion}

The patient in this report represented a rare and atypical case of cryoglobulinemic glomerulonephritis. The uniqueness of this case is underscored by a variety of factors such as his clinical presentation, laboratory and serological studies, and pathology. In contrast to the vast majority of patients with cryoglobulinemia that present with systemic manifestations of cryoglobulinemia, the subject of this report did not have the classic clinical triad of purpura, arthralgia, or weakness. In contrast, the patient was of the minority of patients presenting with renal involvement, characterized a persistent microscopic hematuria and proteinuria as the presenting symptom. Furthermore, while the overwhelming majority of patients presenting with cryoglobulinemia are middle-aged Caucasian females, our patient was an 18yo African-American male without an underlying etiology for cryoglobulinemia. Only a single prior report has demonstrated a diagnosis of cryoglobulinemia in a patient under $20 y[6,49]$. Laboratory and serological studies in cryoglobulinemia generally follow a characteristic pattern - detection of circulating cryoglobulins, low levels of complement, and the presence of rheumatoid factor yet a limited number of cases have presented with varied serological results, similar to the case presented here. Pathological analysis of kidney biopsy samples obtained from our patient demonstrated findings consistent with cryoglobulinemic glomerulonephritis on light, immunofluorescent, and electron microscopy. Importantly histological specimens also demonstrated the presence of a significant number of crescents, a rare pathological finding in the context of cryoglobulinemia and cryoglobulinemic glomerulonephritis. In sum, the case presented here represented a particular diagnostic challenge that required the coordinated efforts of internal medicine, nephrology, and pathology to accurately diagnose and formulate a therapeutic regimen to prevent further decline in kidney function.

\section{Consent}

Informed consent has been obtained from the patient to write this manuscript

\section{Conflict of interest}

The authors have no conflicts of interest to declare

\section{References}

1. Kowalewska J (2011) Cryoglobulinemic glomerulonephritis--lessons from animal models. Folia Histochem Cytobiol 49: 537-546.

2. Mazzucco G, Monga G, Casanova S, Cagnoli L (1986) Cell interposition in glomerular capillary walls in cryoglobulinemic glomerulonephritis (CRYGN). Ultrastructural investigation of 23 cases. Ultrastruct Pathol 10: 355-361.

3. Matignon M, Cacoub P, Colombat M, Saadoun D, Brocheriou I, et al. (2009) Clinical and morphologic spectrum of renal involvement in patients with mixed cryoglobulinemia without evidence of hepatitis C virus infection. Medicine (Baltimore) 88: 341-348.

4. Monga G, Mazzucco G, Casanova S, Boero R, Cagnoli L, et al., Ultrastructura glomerular findings in cryoglobulinemic glomerulonephritis. Appl Pathol 5: 108115.

5. D'Amico G, Colasanti G, Ferrario F, Sinico AR, Bucci A, et al. (1988) Renal involvement in essential mixed cryoglobulinemia: a peculiar type of immunemediated renal disease. Adv Nephrol Necker Hosp 17: 219-239.

6. Cordonnier DJ, Renversez JC, Vialtel P, Dechelette E (1987) The kidney in mixed cryoglobulinemias. Springer Semin Immunopathol 9: 395-415.

7. Feiner H, Gallo G (1977) Ultrastructure in glomerulonephritis associated with cryoglobulinemia. A report of six cases and review of the literature. Am J Pathol 88: 145-162.

8. Fabbian F, Stabellini N, Galdi A, Sartori S, Aleotti A, et al. (2008) Ultrastructura pathology of nephropathies with organized deposits: a case series. Cases $\mathrm{J}$ 1: 184.

9. Iskandar SS, Herrera GA (2002) Glomerulopathies with organized deposits Semin Diagn Pathol 19: 116-132.

10. Tarantino A, Campise M, Banfi G, Confalonieri R, Bucci A, et al. (1995) Long-term predictors of survival in essential mixed cryoglobulinemic glomerulonephritis. Kidney Int 47: 618-623.

11. Beddhu S, Bastacky S, Johnson JP (2002) The clinical and morphologic spectrum of renal cryoglobulinemia. Medicine (Baltimore) 81: 398-409.

12. Tsuboi N, Ichinose M, Kawamura T, Joh K, Utsunomiya $Y$, et al. (2010) Rapidly progressive cryoglobulinemic glomerulonephritis. Clin Exp Nephrol 14: 492 495.

13. Moroni G, Ponticelli C (2014) Rapidly progressive crescentic glomerulonephritis: Early treatment is a must. Autoimmun Rev 13: 723-729.

14. Atkins RC, Nikolic-Paterson DJ, Song Q, Lan HY (1996) Modulators of crescentic glomerulonephritis. J Am Soc Nephrol 7: 2271-2278.

15. Tipping PG, Kitching AR, Cunningham MA, Holdsworth SR (1999) Immunopathogenesis of crescentic glomerulonephritis. Curr Opin Nephrol Hypertens 8: 281-286.

16. Floege J, Topley N, Resch K (1991) Regulation of mesangial cell proliferation Am J Kidney Dis 17: 673-676.

17. Floege J, Burns MW, Alpers CE, Yoshimura A, Pritzl P, et al. (1992) Glomerula cell proliferation and PDGF expression precede glomerulosclerosis in the remnant kidney model. Kidney Int 41: 297-309.

18. Okuda S, Languino LR, Ruoslahti E, Border WA (1990) Elevated expression of transforming growth factor-beta and proteoglycan production in experimental glomerulonephritis. Possible role in expansion of the mesangial extracellular matrix. J Clin Invest 86: 453-462.

19. Meltzer M, Franklin EC (1966) Cryoglobulinemia--a study of twenty-nine patients. I. IgG and IgM cryoglobulins and factors affecting cryoprecipitability. Am J Med 40: 828-836.

20. Meltzer M, Franklin EC, Elias K, McCluskey RT, Cooper N (1966) Cryoglobulinemia--a clinical and laboratory study. II. Cryoglobulins with 
Citation: Haas C, Singh D, Kohan P, Soundararajan S, Aggarwal S (2015) A Rare and Atypical Case of Essential Cryoglobulinemic Glomerulonephritis with Crescents. J Nephrol Ther 5: 220. doi:10.4172/2201-0959.1000220

rheumatoid factor activity. Am J Med 40: 837-856.

21. Ramos-Casals M, Stone JH, Cid MC, Bosch X (2012) The cryoglobulinaemias. Lancet 379: 348-360.

22. Ferri C, Sebastiani M, Giuggioli D, Cazzato M, Longombardo G, et al. (2004) Mixed cryoglobulinemia: demographic, clinical, and serologic features and survival in 231 patients. Semin Arthritis Rheum 33: 355-374.

23. Trejo O, Ramos-Casals M, García-Carrasco M, Yagüe J, Jiménez $S$, et al (2001) Cryoglobulinemia: study of etiologic factors and clinical and immunologic features in 443 patients from a single center. Medicine (Baltimore) 80: 252-262.

24. Tedeschi A, Baratè C, Minola E, Morra E (2007) Cryoglobulinemia. Blood Rev 21: 183-200.

25. Brouet JC, Clauvel JP, Danon F, Klein M, Seligmann M (1974) Biologic and clinical significance of cryoglobulins. A report of 86 cases. Am J Med 57: 775788

26. Satish S, Rajesh R, George K, Elango EM, Unni VN (2008) Membranoproliferative glomerulonephritis with essential cryoglobulinemia. Indian J Nephrol 18: 80-82.

27. Okura T, Jotoku M, Miyoshi K, Enomoto D, Kurata M, et al. (2009) Case of membranoproliferative glomerulonephritis due to essential cryoglobulinemia without hepatitis C virus infection. Geriatr Gerontol Int 9: 92-96.

28. Sargur R, White P, Egner W (2010) Cryoglobulin evaluation: best practice? Ann Clin Biochem 47: 8-16.

29. Mizuochi T, Pastore Y, Shikata K, Kuroki A, Kikuchi S, et al. (2001) Role of galactosylation in the renal pathogenicity of murine immunoglobulin G3 monoclonal cryoglobulins. Blood 97: 3537-3543.

30. Rozin AP, Lewin M, Braun-Moscovici Y, Itzhak OB, Bergman R, et al. (2006) Essential mixed cryoglobulinemia type II. Clin Exp Rheumatol 24: 329-332.

31. Sansonno D, Dammacco F (2005) Hepatitis C virus, cryoglobulinaemia, and vasculitis: immune complex relations. Lancet Infect Dis 5: 227-236.

32. Di Stasio E, Bizzarri P, Casato M, Galtieri A, Fiorilli M, et al. (2004) Cl- regulates cryoglobulin structure: a new hypothesis for the physiopathological mechanism of temperature non-dependent cryoprecipitation. Clin Chem Lab Med 42: 614 620

33. Smith KD, Alpers CE (2005) Pathogenic mechanisms in membranoproliferative glomerulonephritis. Curr Opin Nephrol Hypertens 14: 396-403.

34. D'Amico G, Colasanti G, Ferrario F, Sinico RA (1989) Renal involvement in essential mixed cryoglobulinemia. Kidney Int 35: 1004-1014.

35. Roccatello D, Isidoro C, Mazzucco G, Mesiti A, Quattrocchio G, et al. (1993) Role of monocytes in cryoglobulinemia-associated nephritis. Kidney Int 43 . 1150-1155.
36. Fiorini G, Bernasconi P, Sinico RA, Chianese R, Pozzi F, et al. (1986) Increased frequency of antibodies to ubiquitous viruses in essential mixed cryoglobulinaemia. Clin Exp Immunol 64: 65-70.

37. Fiorini GF, Sinico RA, Winearls C, Custode P, De Giuli-Morghen C, et al. (1988) Persistent Epstein-Barr virus infection in patients with type II essential mixed cryoglobulinemia. Clin Immunol Immunopathol 47: 262-269.

38. Ferri C (2008) Mixed cryoglobulinemia. Orphanet J Rare Dis 3: 25.

39. Bombardieri S, Ferri C, Migliorini P, Pontrandolfo A, Puccetti A, et al. (1986) Cryoglobulins and immune complexes in essential mixed cryoglobulinemia. Ric Clin Lab 16: 281-288.

40. Ferri C, Zignego AL, Pileri SA (2002) Cryoglobulins. J Clin Pathol 55: 4-13.

41. La Civita L, Zignego AL, Monti M, Longombardo G, Pasero G, et al. (1995) Mixed cryoglobulinemia as a possible preneoplastic disorder. Arthritis Rheum 38: $1859-1860$

42. Vallat JM, Desproges-Gotteron $R$, Leboutet MJ, Loubet $A$, Gualde N, et al. (1980) Cryoglobulinemic neuropathy: a pathological study. Ann Neurol 8: 179185

43. Saadoun D, Sellam J, Ghillani-Dalbin P, Crecel R, Piette JC, et al. (2006) Increased risks of lymphoma and death among patients with non-hepatitis $\mathrm{C}$ virus-related mixed cryoglobulinemia. Arch Intern Med 166: 2101-2108.

44. Quartuccio L, Fabris M, Salvin S, Isola M, Soldano F, et al. (2007) Bone marrow B-cell clonal expansion in type II mixed cryoglobulinaemia: association with nephritis. Rheumatology (Oxford) 46: 1657-1661.

45. Vitali C, Ferri C, Nasti P, La Civita L, Mazzantini M, et al (1994) Hypercomplementaemia as a marker of the evolution from benign to malignant $\mathrm{B}$ cell proliferation in patients with type II mixed cryoglobulinaemia. $\mathrm{Br} J$ Rheumatol 33: 791-792.

46. De Vecchi A, Montagnino G, Pozzi C, Tarantino A, Locatelli F, et al. (1983) Intravenous methylprednisolone pulse therapy in essential mixed cryoglobulinemia nephropathy. Clin Nephrol 19: 221-227.

47. Ferri C, Cacoub P, Mazzaro C, Roccatello D, Scaini P, et al. (2011) Treatment with rituximab in patients with mixed cryoglobulinemia syndrome: results of multicenter cohort study and review of the literature. Autoimmun Rev 11: 48-55.

48. Zaja F, De Vita S, Mazzaro C, Sacco S, Damiani D, et al. (2003) Efficacy and safety of rituximab in type II mixed cryoglobulinemia. Blood 101: 3827-3834.

49. Ben-Bassat M, Boner G, Rosenfeld J, Pick Al, Kahana M, et al. (1983) The clinicopathologic features of cryoglobulinemic nephropathy. Am J Clin Patho 79. 147-156. 